\title{
The Digital Economy of the Sourdough: Housewifisation in the Time of COVID-19
}

\author{
Julianna Faludi* and Michelle Crosby** \\ *Corvinus University of Budapest, Budapest, Hungary, faludisociology@gmail.com, \\ www.juliannafaludi.com
}

${ }^{* *}$ Corvinus University of Budapest, Budapest, Hungary, michelleo.crosby@gmail.com

\begin{abstract}
The most brilliant part of re-visiting Engels, were the stark reminders, sometimes paragraph by paragraph, of key, essential truths that remain valid today in 2020 regarding new (perhaps old, but now more visible) forms of housewifisation, unto which SARS-CoV2 has shown a mirror to every person who has ever concerned themselves with gender in-balance, lay person to expert. This paper is about justifying those claims as essential truths by drawing modern parallels and also intends to generate a discussion on the form of the family and societal organisation which would support human flourishing, regardless of gender by formulating a new, post-COVID gender order.
\end{abstract}

Keywords: housewifisation, digital economy, exploitation, Engels, SARS-CoV2

Acknowledgement: The authors acknowledge the reviewers of the first drafts of this paper affiliated with the Karl Polányi Research Institute, and the editor of the special edition of tripleC.

\section{Introduction}

This paper takes under scrutiny the new forms of exploitation and housewifisation in digital capitalism in the context of the pandemic-lockdowns. The home office has overturned what we know and think about digital work, as the workplace has been replaced to homes, along with several functions, like schooling and social services being provided beforehand by the state and market structures. It is not the Internet economy that exploits people related to the restrictions, it went further, people take on the burden of the state, the costs of schooling etc., while the state enforces and extends its surveillance to monitor the communication and the location of people.

From a theoretical perspective, this has implications on at least two levels: we need to reconsider where we place the role of the state, the role of the exchange value of goods, and the role of money in this economic circuit as forms of alienation. Furthermore, we need to understand the role of digital labour and the shifting societal division of labour. Public spending cuts have been visible in the budgeting of policy programmes, but domestic work has been always just estimated due to a lack of systematic data being gathered on the national level. The outsourcing of schooling and social services along with the home office has created a new trend of housewifisation. Mies $(1982 ; 1986)$ found that homeworkers were superexploited, denied social security, and often poor. Her study of lace makers in India revealed that homeworkers who were producing lace in a putting-out system were paid low wages based on the ideology of the housewife, which legitimised the superexploitation of women at home with wages below the subsistence level (Mies 1982). According to Mies's (1986) theory the rise of capitalism under patriarchy, capital sees women, nature, and the colonies as standing 
outside of civilised society and therefore treats them as cheap sources of value. Mies $(1986,112-116)$ argues that in the $19^{\text {th }}$ and $20^{\text {th }}$ centuries the construction of the housewife went through two main stages: first the creation of the women of the accumulating classes who consume luxury goods and as bourgeois housewives are agents of consumption. And second, proletarian women who became the "colony" of white men . They labour in the nuclear family. Only the class of the wealthy could afford to have a family. The bourgeoisie declared "family a private territory in contrast to the 'public' sphere of economic and political activity" (Mies 1986, 104). Prügl $(1996,115)$ a decade later in an empirical work explored different socio-economic contexts from the perspective of colonisation and confirms that women defined as housewives "have become the optimal flexible labour force".

Today, the housewife is represented with the image of the sourdough-bread baking woman. The load of unpaid work and waged labour has grown, and advances the selfexploitation of the "housewife".

Since contemporary societies have love-driven, and interest-driven marriages in their diverse forms, we need to look at the institution of marriage and other forms of cohabitation from the perspective of: 1) economic organisation as a driving force behind these institutions; and 2) institutional evolution itself. Institutional evolution implies that cohabitation exists in society in one given time period as a heritage of previous times, when given forms have emerged and established themselves, as well as new forms that emerge organically in the given era, but are being perceived as innovations, thus not being wide-spread and are being tied to some social groups within the society.

\section{Digital Pairing}

Engels in his work on The Origin of the Family, Private Property and the State (1891a) tied the place of sexuality in the society to two essential drivers. The changing environment, such as the extinction of the huge mammals due to over-hunting, created disruptions within the communities. Hunting communities of people had to be segmented to smaller groups in order to survive. Male-dominance emerged by males taking control over organising symbolic rituals around the resource-provision from females. Thus, changing conditions pushed people to economic re-organisation, and to re-arrange their customs that affected the modes of reproduction. New instruments of production had to be created for survival, and this technological advancement was tied to the reshuffling of social relations of humans. Biological entities that went through a natural evolution, had been pushed to civilising themselves into a culture of private property and domesticated sex with one partner - forming a household, also known as paired marriage.

In the longer term, this shift commodified the marital status. Exchange of the "female" in return for economic benefits, added exchange value - the bride price - to females being bought from their families. The commodification of women for creating heritage and wealth in the long run, and rendering marriage itself into the market domain - went a long way, and was present during the processes of industrialisation and the birth of capitalism. The pre-condition for class societies to emerge was the creation of forms of oppression, where monogamy - one-sided as being expected mostly from women - was a tool to break community surveillance and (sisterhood) solidarity to give way to competition and appropriation of wealth and resources. The institution of private property is at the core of dissolving communities - a law of Marxist logic that is also valid for intimacy, and the "privatising" process of human sexuality, and privatisation of intimacy has creeped along during modernisation. 
For example, forms of cohabitation might be tied to social class, but in contemporary societies, the liberalisation of the legitimised forms goes along with the conservative de-legitimation process of the variations of cohabitation. Marriage and diversity of sexuality have become a commodity deployed by political elites enforcing agendas within the socio-political domain. This can be seen as a political enforcement rather than an economic one, given that the aim is not purposefully creating efficient economic organising - think of what the household as an economic unit meant for the market and the state in the mid- and late 20th century. The aim of political commodification of forms of cohabitation and individual sexuality is the creation of a stable electoral base in the short and mid-term, and the creation of content for feeding the masses. In this regard it is no less than the creation of other thematic content within the political social-mediatised communication. Sexuality and cohabitation have left the private domain. The life of people living together could remain in the private zone only for a shorter period of time, and mostly in urbanised and economically prospering geographical areas. This does not imply that these spheres have not been controlled domains before, but the trends of loosening the social norms around sexuality and then pulling them back just to create a social discourse to feed the content-driven public is a phenomenon of the $21^{\text {st }}$ century. Sexuality - such as sexual preferences of the individual or the structure of families and the role of women - are a political commodity that thematises public discourse on sexuality in the media and on social media in the context of digital capitalism and social media society.

Another example is the notion of "content is king" - attributed to Bill Gates in 1996 (published on the website of Microsoft ${ }^{1}$ ), described precisely in the advent of today's era that the Internet belonging to communities and people for free-gazing would become soon a marketplace for commodities such as content. By content Bill Gates meant entertainment that can reach out to a vast audience with zero marginal costs and can be duplicated as much as one likes. News magazines would be structured around interactivity - an increased number of clicks and chat discussions - and defined by content in a way that print would never be able to.

Sexuality has come across multiple commodification processes, where the final stage is the marketplace for partners, the culture of swiping images of potential dates, being referred to as swiping culture. This can be linked to various motivations, such as finding a long-term partner, but mostly it serves the "hookup culture" of casual dating that is organised with the help of platforms and apps such as Tinder. Hookup culture has been around since the 1920s, but social media platforms accelerate the encounters individuals might have within a limited time span, by serving a present need of individuals - young women and men - not looking for a stable relationship due to plans of studying, working, etc.

In digital capitalism, time is commodified by the attention-deficit economy. Visibility is turned into an added value of the persona - the public social media image of the individual. Dating platforms have converted the individuals into "hunters" deploying the benefits of swiping and hooking up with a broad number of available targets, while these hunters themselves are not recognising the commodification of their own sexualised image. Capitalist platforms such as Tinder, Bumble, or Hinge are ripping the economic benefits of this exchange.

Distancing and the severe border-lockdowns across countries, regions and districts has separated some couples and locked other couples unexpectedly in one space.

${ }^{1}$ https://medium.com/@HeathEvans/content-is-king-essay-by-bill-gates-1996-df74552f80d9 
The COVID-economy on the one hand enhanced porn-consumption ${ }^{2}$ that was fuelled by the availability of free-content provided by some of the platforms, like Pornhub (Mestre-Bach et al. 2020), and changed the dating habits and intimate relations on the other hand (Dewitte et al. 2020). According to Seidman, the boss of the largest dating social media platform Tinder ${ }^{3}$, lockdown has brought an increase in swipes with a "dramatic shift in behaviour metrics", but falling subscriptions to the premium services of the app. Virtual dating became popular on platforms like eHarmony, OKCupid and Match supporting video dating options, pushing Tinder to expand its services for organising dating events online rather than serving offline dating matches. Dating apps in sum were reported growing and becoming more virtual ${ }^{4}$ as a consequence, after the initial drop in subscribers but a rise in online activity. The shifts in services, such as the passport function on Tinder, and user behaviour also suggest that virtual meaningful connections became important and more location agnostic compared to the previously experienced fast matching. The longer-term effects of these changes are yet to be explored, and it is not clear how virtual meaningful dating will shape behaviour in the future, and if it has any impact on the traditional or now-known institutions of cohabitation and the geography of matching. What can be seen is that the conditions of physical distance, insecurity and alienation have brought together some couples, yet further alienated others.

\section{Digitised Monogamous Pairing Households}

The economic organisation as a driving force behind the creation of the households was and is a persistent model, with some degree of shift in the centrality of the household to the larger economy of firms. In primitive communism however, human reproduction was driven by sexuality, and in Engels' view allowed for parity of the sexes. He supports Bachofen's assertion that the shift from mother-right to father-right downgraded status of women: "women, who, as mothers, were the only definitely ascertainable parents of the younger generation, were treated with a high degree of consideration and respect, which, according to Bachofen's conception, was enhanced to the complete rule of women (gynaecocracy)" (Engels 1891b, 205). Sisterhood and solidarity among women, and among men would create large families, and save individuals from domestic or sexual violence. Social norms were under close scrutiny within the community, especially when the institution of abolishing incest emerged. Power did not break societies into classes yet, as the main function of the community was not accumulation of wealth but rather human reproduction. Contemporary societies that are shaped by digital capitalism in the social media age do not focus on biological human reproduction but on capital accumulation mediated by digital technologies.

Modern families have found themselves locked in their homes in a family structure that turned out to be efficient and dysfunctional at the same time in so many ways. Stories about the obstacles in meeting extramarital dates, reports about increased

${ }^{2}$ https://www.economist.com/international/2020/05/10/pornography-is-booming-during-thecovid-19-lockdowns

3 https://www.bbc.com/news/business-52743454

4 https://www.emarketer.com/content/love-time-of-coronavirus-dating-apps-growingbecoming-more-virtual 
home-abuse, and the increased tendency of divorce have drawn attention to the dysfunctions of the persistent structure. UN Women reported ${ }^{5}$ that there was a significant increase at least in $50 \%$ of the countries in reports to the police, health centres, helplines after the outbreak of the COVID-19, in other countries there was a decrease due to the restrictions in mobility. Particularly vulnerable became women with disabilities or those who recovered from COVID-19, and returning migrant women facing exclusion and stigmatisation in the communities. Among the exacerbating factors are the isolation with the abusers, security and money worries, and deserted public spaces.

Engels and Marx viewed the transformation of relationships of genders and the family from the perspective of social transformation and economic organisation. The industrial revolutions tore men from their families, that as a consequence reinforced the gendered division of labour in households. Expanding the view on families in the context of the social changes and the complex economic transit of the COVID-19 economy, relationship patterns are defined by the accelerated digitalisation processes and the collision of the public ad privat -social spaces in the home. Households became central, and families became the sole functional economic unit for filling in the gap imposed by the state (schooling, social services, healthcare) efficiently only in cases where a more equalising division of labour has occurred in the household. A report from Turkey ${ }^{6}$ suggests that men's unpaid work time went up nearly five-fold during the lockdown, especially among those who switched to the home office. The increased demand for household production and caring labour has brought a necessity of participation of most family members. Yet women were still performing four times more unpaid work than men.

A survey ${ }^{7}$ (Weissbourd et al. 2020) found that fathers felt closer to their children during the lockdown, across race and class in the US. An analysis conducted in the UK conducted in March and April 2020 revealed that fathers reported to do 58\% more childcare work than normally (ONS 2020). The report also reveals that fathers would need more flexible working arrangement for participating more in childcare, and that they feel their jobs would be more threatened than women's when asking for remote working solutions at their workplaces.

Shifting towards the home as the central economic system generated increased demand for housework on women as there was a need to create a space for childcare provided by men. Thus, men were more prone to take over childcare time from women than performing housework. Still, the increase of time spent by men on childcare is a trend to consider when thinking about the new family structure. Yet, we argue that these processes may create a deepening mediatised "housewifisation" since "old institutions" still prevail. Mies (1986) sees housewifisation as the devaluation of women's unpaid and underpaid work, as an underlying accumulation model of the capitalist world economy.

${ }^{5}$ Impact of Covid-19 on Violence Against Women and Girls and Service Provision. UN Women Rapid Assessment and Findings. https://www.unwomen.org/-/media/headquarters/attachments/sections/library/publications/2020/impact-of-covid-19-on-violence-againstwomen-and-girls-and-service-provision-en.pdf?la=en\&vs $=0$

${ }^{6}$ https://www.tr.undp.org/content/turkey/en/home/library/corporatereports/COVID-gender-survey-report.html

${ }^{7}$ https://static1.squarespace.com/static/5b7c56e255b02c683659fe43/t/5eeceba88f50eb1981 0153d4/1592585165850/Report+How+the+Pandemic+is+Strengthening+Fathers+Relationships+with+Their+Children+FINAL.pdf 


\section{4. "Old Institutions" in Modern Monogamous Pairing}

As an illustration of the persisting old institutions that may prevail in the forms of tradition in society are rituals or customs being followed in the framework of the ceremony in the offline domain. Engels placed the marriage by capture in the evolution of marital relationships at a time when gender-based dominance was about to emerge, but matrilineal households still persisted. He writes, "the abduction of women reveals even here a trace of the transition to monogamy - at least in the form of the pairing marriage" (Engels 1891a, 155). The man who lead the ritual of capturing a woman from the other group - either to avoid incest, or to perform dominance over the others - would have the woman for himself after ceasing her. What is described there is a gang rape, where the males of the "hunting" group would demonstrate their dominance over her body. Engels places this custom in the era which he describes as one where women were leaders and respected within the community. But what is not mentioned is that the respected role of leadership was given to in-group females in power-position.

The tradition of "stealing the bride" or "snatching the bride" or kidnapping the bride in some Eastern-European cultures such as Hungary and in the Caucasus is connected to the above described ritual. Molodikova (2013) found that these traditions are still a social reality. The stories of the brides reveal their oppressed status that defines the course of their lives as being forced into marriage and motherhood instead of pursuing their studies, etc.

Some rituals from the times of the marriage by capture have remained until today just like inheritance that for many is until today almost the only way to accumulate wealth. These are structures that have been persisting since the times of the industrial revolutions (Piketty 2013). In pre-class communal societies oppression and arrangement of people into classes came about as a necessity to adapt and to develop new instruments of production. How to adopt to the new challenges today faced by families, and who are the families that we are talking about is yet a question to understand in the wake of the crises since "old institutions" that emphasise self-protection from the market can still be observed.

Communist households that include multiple generations living in the same house can be found in Hungary and other Central and Eastern European countries. This is known as "ket-generacio" or "two-generation". Multi-generation households in the US are perceived as being traditionally reserved to the poor; most probably persons of colour, especially the working class and immigrants, precisely for their protective benefits. Two-generation homes are sometimes coupled with another protection from the market, the Hungarian "homestead", which includes a rich garden - essentially a fully functioning farm with peach trees, fig trees, grapes, tomatoes, chicken, a turkey, other kinds of fowl and domestic farm animals. During Hungarian State Socialism, families used these self-sustaining homesteads as a mechanism against food insecurity and shortages.

Making bread and yogurt in-house, filling cases with kolbasz and even distilling palinka is in Hungary a symbol of pride and self-sufficiency. It is done on top of the care work that is primarily conducted and coordinated by women. To make each household its own factory, rather to outsource or engage with outside places of exchange, requires full-time workers and traditionally large families. COVID-19 re-legitimised these practices similar to the way a "reserve army"' is justified in war-time contingency plans. 


\section{The COVID-19 Economy, Digital Households and Alienation}

In primitive communism, women had strong bonds to exercise power over non-cooperative males. The family was a place where work was shared among the members of the family, the division of labour was a functional one and inherent to the community. That was the point in human history when oppression among individuals was not yet systemic. Marxism sees the family as one of the fundamental units of capitalism, due to its economic unit role, as well as its reproductive role. Engels writes: "The social institutions under which men of a definite historical epoch and of a definite country live are determined by both kinds of production: by the stage of development of labour, on the one hand, and of the family, on the other" (Engels 1891a, 132).

Instead of the image of women being captured and ravaged by friends of her captor, ripped from her tribe, women's role today is more pleasantly re-framed as superwoman. Superwoman, an icon of power, superiority and strength, is frequently referenced as a symbol of female potential, but most importantly presents society's expectations of paired females. Essentially, there are women who volunteer for self-exploitation, defined as the institutionalised slavery of women in the monogamous paired family. The Superwoman Syndrome is a mythical ideal of women inside monogamous paired marriage. The content of the superwoman ideology is that women perform fantastic feats that are posted on social media. This ideology is the carcass upon which the eating machine, the digital economy, both feasts and gains momentum. Women desire to be seen as heroes, "doing it all". A friend remarked: "I am happy with the shift to digitalisation because then I'll be able to teach and go to conferences when the children are sick".

The digitalised household economy is the combination of home-office, homeschooling, and social media image-construction of the individuals. This imposes new roles: those of the "civilised" world out there: family members become co-workers and the home becomes a co-working space and school. Children and parents become students and teachers. Roles that were outsourced to "society" to be provided mostly by the state. These roles became controlled by the framework regulated by the state/ employer outside regulations, and being outsourced to be enforced within the family. The division of labour in the family is imposed by external structures and enforced by the internal split of roles. Alienation spreads from work to home now that workplaces spread into the digitialised household. Alienation has grown to an unprecedented level. The COVID-19 lockdown advanced alienation in the home. A state-enforced familyorchestration pushed families to take on education, healthcare and social services that had been delegated from state-provision to families. Child-rearing as a process internalised to the nuclear family took on an externalised function of education: distant and digital learning has left families with home-schooling and forced parents to take over the school's role with external requirements that pupils have to comply with.

For the first time since industrialisation, the firm is not the central unit of analysis, but rather society has gone back to its roots, to the household. Presently, paid and unpaid labour lack the spatial divide they have previously enjoyed, making female and male contributions (or the lack thereof) more visible. During COVID-19, women were putting food into the oven for their children's lunch with a computer on top of the toaster and the oven so that the headset cord would stretch sufficiently while bending over during an online meeting or webinar. Children completed their school lessons at the small table in the kitchen. We were teaching the children, making money to buy food and the electricity that powers our homes.

The blurring of private and public spheres of life has been underway for some decades now (Dén-Nagy 2018). Among managers, to be always available over and above 
the paid hours of employment is an expectation and requirement for promotion. Since women of child bearing age perform the majority of unpaid labour, they are not available for these additional hours of unpaid paid labour. In addition, the solution isn't a simple matter of her husband leaning in to the household duties, because he himself is occupied with on-demand labour during non-working hours. While it is tempting to blame institutions for such impositions, we must remember that bias is unconscious, and it is men who control most positions of power in capitalist society so that unpaid paid labour is a mechanism for female oppression that comes on top of wage inequality that women face.

The distancing of individuals from collectives, i.e. individualisation, has also been a generation-defined trend that has been worsening for some time. Communities that gave place to a looser structure of neighbourhoods and atomised families, in the fifties and sixties drove people further from affiliating with politics and turning toward civic organisations and religious groups, as explained by Putnam (2000) in the book Bowling Alone. In the early-fifties Nisbet warned about the central state filling in the role of the community if family, church or locality would not be able to fulfil the desires of humans for community. The desire for community has been challenged by the new form of alienation that has been labelled as social distancing in the context of COVID-19 prevention.

Rituals of people-to-people interaction gave path to newly emergent structures, and digital connection more than before is the key social network of humans. The encounter with people one trusts in less distancing encounters is in the pandemic crisis organised as a looser network of virtual connections. There are many stories circulating about the lengthy virtual talks and meetings bringing people closer under the lockdown, which is supported by the shifts in the social and dating media usage behaviour. Digital means of communication create virtual communities that are less defined by the locality, while locality under lockdown and other restrictions of physical social interaction narrows locality to the home and neighbourhood. Families are in this context especially important for the organisation of belonging. The structure and embeddedness of the contemporary family in society places community in the backstage. Authority remains in the hands of the family and reinforces the role of the state. Virtual communities are dispersed, and not suitable for monitoring and ensuring social norms. The COVID-19 economy of digital capitalism enhances state surveillance of individuals and the alienation within families.

The loss of jobs, the shifting of jobs to the home and the acceleration of shifting exchange onto digital platforms have implications for the societal division of labour. Guest workers from Romania and Bulgaria were flying to Germany and Austria to ensure that agricultural and food processing production would continue and there was not disturbance of food supply on the market. Workers forced to live in crowded spaces and work under conditions not in compliance with the pandemic-safety considerations were most vulnerable to mass infections, that was predictable from the beginning.

During the lock-down in spring 2020, some large organisations hiring skilled labour transitioned to the Microsoft Teams platform, where communications were inundated by notifications and pop-ups. In addition, features allowed for time tracking and for a notification to appear when a certain person "appears online". A dialogue about abnormal expectations of synchronous work started to emerge; namely, that one could not discharge their functions as if the computer was simply moved from the office to the kitchen table. Toggling between the old "unpaid" labour and "paid" labour, employers perhaps began to panic that they were paying employees for "unpaid" work and started 
to increase surveillance and monitoring. Furthermore, they no longer received the unpaid paid labour that they previously enjoyed and that increased their profits through what Marx terms absolute surplus value production - the lengthening of the working day and of the increase of the amount of unpaid labour conducted per day.

Marxism defines the private property that drives the institution of the family as one of the core problems of inequalities within society and in families. The abolition of the family as a quest of Marx addressed a broader problem, it was a call for liberating individuals from inequality and systematic oppression, as well as creating space for communities that would represent a flattened structure of society. But what are the driving forces behind virtual communities?

\section{The Economy of the Sourdough in Digital Capitalism}

The outsourcing of schooling and social services along with the home office has created a new housewifisation trend. Women baking sourdough bread and posting images of it on Instagram during the COVID-19 lockdown are symbols of this new phase of housewifisation. The lockdown has just highlighted and reinforced how the economic circuit has become even more sophisticated in producing meanings to goods that have become even more abstract.

Mies $(1986,103)$ argues that the domestication and privatisation process of the housewife in the $19^{\text {th }}$ century fostered the construction of the image of the "good woman'. The COVID-19 lockdown confined women to the household where a set of housework chores had to be performed. We argue that the images of home-baked bread trending on social media during the time of the pandemic is a symbol of this contemporary domestication process that creates a certain image of the good woman leveraging between her paid and unpaid jobs. The privatised arena of consumption at home is exposed to digital communities.

Home-baked bread, a trend that swept across social media, sourdough and yeast have become scarce commodities (along with toilet paper). The public presentation of the self was recognised as being immanent to the capitalist mode of production (Read 2003) before the spread of social media in all sectors of economic organisation. The economic circuit thus captures the presentation of the self into a lock-in: images of a kind are being reproduced by the users for various reasons to present the informed image of the self and accumulate social capital. The trend of posting home-baked bread images online was based on the logic of precarious labour. There was a boost the sales of kits and packages designed for producing home-baked bread offered by bakers. There were also tutorials and live streamings.

Yeast and flour shortage hit the stores in March and April 2020 across the world. Bread is the symbol of survival, hospitality, and abundance that is deeply rooted in history. It represents culture, the miracle of agriculture and human ability to process grains, and cultivate sourdough or yeast to convert it into an edible product. Rituals of celebration of bread are part of numerous traditions. Civilisation is tied to the spread of organised agriculture, so is the rise of paired marriages and the patriarchal family, and the beginning of serfdom of women according to Engels. He writes, "Within the family he is the bourgeois; the wife represents the proletariat" (Engels 1891a, 181). Bread-baking was an inherent part of housework, a labour-intensive activity of the mother undertaken for feeding her family. With the increased division of labour in industrial societies, bakers became important players in the urban economy. Durkheim (1996; 1893) uses the image of the baker for illustrating how different household tasks have been taken over by newly emerging professions. Placing the bread back to the homes was not just the result of the "slow"-branded economy, but a response to the 
lockdown. The emerging community around home-based bread-baking was a globalised way of transmitting meanings of locality, home, and community at the time of the shock of the pandemic. The meaning of bread and the performing proficiency of breadbaking were forms of demonstrating culinary capital and an act of the social positioning of oneself (Easterbrook-Smith 2020). This also highlights how despite physical localisation globalisation is unfolding in the enhanced digital reality of the COVID-economy.

The competition of the home-bread beakers went along with proud images of all types of home-baking and cooking that presented the meritocratic message accomplishment. The processes of self-branding formalised by reality television and enhanced by the social media according to Hearn (2016) has intensified and

spread across the population at large. Indeed, the popularity and ubiquity of social media seem to confirm the centrality of socialized production, flexible, immaterial and affective labor and capitalism's "new" hidden abode of production (Hearn 2016, 11).

Digital reputation is a way of reinforcing the newly made "housewife" whose work is rendered invisible and being inaugurated as a new kind of labour in social media. Hearn argues that in the $21^{\text {st }}$ century this type of value creation is done in ways that are deeply gendered and recall the appropriation of women's work "inside and outside of the home by systems of capitalist expansion in the $16^{\text {th }}$ and $17^{\text {th }}$ centuries" (Hearn $2016,2)$. This lies in the logic of precarious and affective labour where the digitialised forms of human subjectivity are mingling with new forms of production. The socialisation of labour is a form of promotion of precarious forms of exploitation hiding the reality of the digital housewifisation processes accelerated by the lockdown. The mediatised vision of labour is structurally free of cost as labour and the invisible labour of housewives form a source of exploitation as a naturally occurring good (Mies 2007, 269).

The reality though was in contrast with this image for many affected severely by the lockdown either due to the loss of income and the pressure for survival, or the overwhelming tasks imposed on families confined to the home office. Decreased mobility in public spaces confined many to stay at home with abusive family members, moreover abusive tendencies were reported to rise as a consequence of the mental health crises that emerged due to the lockdown. The process of housewifisation and the shift of precarious and (paid) work on women confined to their homes has brought several consequences, that are the subject of contemporary studies.

What we know is that this process has been radical and affected the masses (Fuchs 2020). What we also know is that along with the burnout, the need for "catching up" and the "fear of missing out". parents with families have to push themselves toward performing more. Colleagues with no families had the space for working from home in a calm environment boosting their performance. Parents with children may have felt disproportionately hindered in their performance finding themselves worried about the future of their careers.

This type of slavery pushed many toward putting more self-imposed chains, selfexploitation, on themselves. The shift of performance to digital platforms has opened the path for self-slavery, voluntary servitude, as mode to transgress "obstacles of growth". The decelerated public life in the public physical space has accelerated forms of self-deployment. Wage-work and non-wage work have transgressed the boundaries of personal space deploying the remnants of personal and family time. Wages have not increased, placing more labour demands on the workers fighting to keep their jobs. In the wake of the lockdowns optimistic views on newly-gained space for solidarity in 
the society along with the perceived threats of alienation have been expressed (Fuchs 2020). By the last quarter of 2020 we see that some economic sectors have been affected more severely than others, deepening class divisions in societies.

\section{Conclusion}

The dissolving of physical spaces during the COVID-19 crisis reinvigorated a basic idea of Marx and Engels; namely, the delimitation between paid and unpaid labour, public and private spheres. We can observe spill-overs across spheres more closely as women are exploited in a two-fold manner during the COVID-19 crisis. We demonstrate that spill-overs have crept up on us slowly: There is the exploitation of women in the digital economy that is mediated by social media. And there is voluntary exploitation due to women's desire to achieve "the ideal pair" of superwoman in monogamous, paired marriage. This paper serves as a reminder of the blurring of social spheres and their gendered demarcations, as we witness the return to the household as the central unit of society. This shift provides evidence that the essential truths presented by Engels in the $19^{\text {th }}$ century can be employed to understand our reality during the COVID crisis.

What applies to the woman in the factory applies to her in all branches of business, right up to medicine and law. The modern individual family is based on the overt or covert domestic slavery of the woman; and modern society is a mass composed solely of individual families as its molecules (Engels 1891a, 181).

\section{References}

Dén-Nagy, Ildikó. 2018. Problem Solver or Private Life Killer? Mobile Telephony and WorkLife Balance in Hungary. PhD Thesis. Budapest: Budapest Corvinus University, Sociology Doctoral School.

Dewitte, Marieke, Chantelle Otten, and Lauren Walker. 2020. Making Love in the Time of Corona - Considering Relationships In Lockdown. Nature Reviews Urology 17: 547-553

Durkheim, Emile. 1893. The Division of Labour in Society. Trans. W. D. Halls, intro. Lewis A. Coser. New York: Free Press.

Easterbrook-Smith, Gwyn. 2020. By Bread Alone. Baking as Leisure, Performance, Sustenance, During the COVID-19 Crisis. Leisure Sciences. Online First.

Engels, Friedrich. 1891a. The Origin of the Family, Private Property and the State. In the Light of the Researches by Lewis H. Morgan. In Marx \& Engels Collected Works (MECW) Volume 26, 129-276. London: Lawrence \& Wishart.

Engels, Friedrich. 1891b. To the Early History of the Family (Bachofen, McLennan, Morgan). Preface to the Fourth German Edition of The Family, Private Property, and the State. In Marx \& Engels Collected Works (MECW) Volume 27, 203-214. London: Lawrence \& Wishart.

Fuchs, Christian. 2020. Everyday Life and Everyday Communication in Coronavirus Capitalism. tripleC: Communication, Capitalism \& Critique 18 (1): 375-399.

Hearn, Alison. 2016. Witches and Bitches: Reality Television, Housewifization and the New Hidden Abode of Production. European Journal of Cultural Studies 20 (1): 10-24.

Mestre-Bach, Gemma, Gretchen R. Blycker, and Marc N. Potenza. 2020. Pornography Use in the Setting of the COVID-19 Pandemic. Journal of Behavioral Addictions 9 (2): 1-3.

Mies, Maria. 2007. Patriarchy and Accumulation on a World Scale - Revisited (Keynote I'Lecture at the Green Economics Institute, Reading, 29 October 2005). International Journal of Green Economics 1 (3-4): 268-275. 
Mies, Maria. 1986. Patriarchy and Accumulation on a World Scale. Women in the International Division of Labour. London: Zed.

Mies, Maria, 1982. The Lace Makers of Narsapur: Indian Housewives Produce for the World Market. London: Zed.

Molodikova, Irina. 2013. Growing Up in the North Caucasus Society, Family, Religion and Education. Abingdon: Routledge.

Nisbet, Robert. 1953. The Quest for Community: A Study in the Ethics and Order of Freedom. New York: Oxford University Press.

Neilsen, Brett and Ned Rossiter. 2008. Precarity as a Political Concept, or, Fordism as Exception. Theory, Culture and Society 25 (7-8): 51-72.

ONS. 2020. Coronavirus and How People Spent Their Time Under Lockdown: 28 March to 26 April 2020. London: Office for National Statistics.

Piketty, Thomas. 2013. Capital in the 21st century. Cambridge, MA: Harvard University Press.

Prügl, Elisabeth. 1996. Home-Based Workers: A Comparative Exploration of Mies's Theory of Housewifization. Frontiers: A Journal of Women Studies. 17 (1): 114-135.

Putnam, Robert D. 2000. Bowling Alone. The Collapse and Revival of the American Community. New York: Simon and Schuster.

Read, J. 2003. The Micro-Politics of Capital: Marx and the Pre-History of the Present. Albany, NY: State University of New York Press.

Weissbourd, R., Batanova, M., McIntyre, J., \& Torres, E. 2020. How the Pandemic is Strengthening Fathers' Relationships With Their Children. Accessed 9 November, 2020. https://mcc.gse.harvard.edu/

\begin{abstract}
About the Authors
Julianna Faludi $P h D$

Julianna Faludi is a Sociologist interested in the relationship of Science, Technology and Society and Ethical Consumption. Her recent research interest unfolds around Social Innovation and Digital Entrepreneurship for Social Good.

Michelle Crosby

Michelle Crosby is an active Social Scientist with background in Research Methods and Evaluation working in the international affairs industry. She is interested in Teaching, Critical Theory and Analysis, Quantitative Research, Qualitative Research and Research Design.
\end{abstract}

